\title{
Improving growth rates in preweaning calves on dairy farms: A randomized controlled trial
}

Robert M. Hyde, ${ }^{\circledR}($ Martin J. Green, (ㄷ) Chris Hudson, (1) and Peter M. Down (이

School of Veterinary Medicine and Science, University of Nottingham, Sutton Bonington Campus, Leicestershire, United Kingdom LE12 5RD

\section{ABSTRACT}

Previous research has identified key factors associated with improved average daily gain (ADG) in preweaning dairy calves and these factors have been combined to create a web app-based calf health plan (www .nottingham.ac.uk/herdhealthtoolkit). A randomized controlled trial was conducted to determine the effect of implementing this evidence-based calf health plan on both productivity and health outcomes for calves reared on British dairy farms. Sixty dairy farms were randomized by location (North, South, and Midlands) to either receive the plan at the beginning (INT) or after the end of the trial (CON) and recorded birth and weaning weights by weigh tape, and cases of morbidity and mortality. Calf records were returned for 3,593 calves from 45 farms (21 CON, 24 INT), with 1,760 calves from 43 farms having 2 weights recorded $>40 \mathrm{~d}$ apart for ADG calculations, with 1,871 calves from 43 farms born $>90 \mathrm{~d}$ before the end of the trial for morbidity and mortality calculations. Associations between both intervention group and the number of interventions in place with ADG were analyzed using linear regression models. Morbidity and mortality rates were analyzed using beta regression models. Mean ADG was $0.78 \mathrm{~kg} / \mathrm{d}$, ranging from 0.33 to $1.13 \mathrm{~kg} / \mathrm{d}$, with mean rates of $20.12 \%$ (0-96.55\%), $16.40 \%$ (0-95.24\%), and $4.28 \%(0-18.75 \%)$ for diarrhea, pneumonia, and mortality. The INT farms were undertaking a greater number of interventions (9.9) by the end of the trial than CON farms (7.6). Mean farm ADG was higher for calves on INT farms than CON farms for both male beef $(\mathrm{MB},+0.22 \mathrm{~kg} / \mathrm{d})$ and dairy heifer $(\mathrm{DH},+0.03$ $\mathrm{kg} / \mathrm{d}$ ) calves. The MB calves on INT farms had significantly increased mean ADG $(0.12 \mathrm{~kg} / \mathrm{d}, 95 \%$ confidence interval: 0.02-0.22) compared with CON farms. No significant differences were observed between interven-

Received July 1, 2021.

Accepted September 27, 2021.

*Corresponding author: robert.hyde4@nottingham.ac.uk tion groups for morbidity or mortality. Implementing one additional intervention from the plan, regardless of intervention group, was associated with improvements in mean ADG for DH calves of $0.01 \mathrm{~kg} / \mathrm{d}(0.01,0-0.03)$ and MB calves of $0.02 \mathrm{~kg} / \mathrm{d}(0.00-0.04)$. Model predictions suggest that a farm with the highest number of interventions in place (15) compared with farms with the lowest number of interventions in place (4) would expect an improvement in growth rates from 0.65 to $0.81 \mathrm{~kg} / \mathrm{d}$ for $\mathrm{MB}$, from 0.73 to $0.88 \mathrm{~kg} / \mathrm{d}$ for $\mathrm{DH}$, a decrease in mortality rates from $10.9 \%$ to $2.8 \%$ in $\mathrm{MB}$, and a decrease in diarrhea rates from $42.1 \%$ to $15.1 \%$ in $\mathrm{DH}$. The calf health plan tested in this study represents a useful tool to aid veterinarians and farmers in the implementation of effective management interventions likely to improve the growth rates, health, and welfare of preweaning calves on dairy farms.

Key words: randomized controlled trial, calf health, daily live weight gain, average daily gain

\section{INTRODUCTION}

The health and performance of dairy and beef cross calves reared on dairy farms is important (Windeyer et al., 2014), both in terms of welfare (Renaud et al., 2018) and economics (Boulton et al., 2017; Mõtus et al., 2017). Recent research in the United Kingdom found that during the preweaning period, $48 \%$ of UK calves experienced diarrhea and $46 \%$ experienced respiratory disease (Johnson et al., 2017). Variations in ADG have also been reported in calves from UK dairy herds (Bazeley et al., 2016). Dairy farmers often rank youngstock health as a lower priority than the health of adult cows (Atkinson, 2015), and although the economic importance of female dairy replacement animals is well known (Brickell et al., 2009; Hultgren and Svensson, 2009; Boulton et al., 2017), previous research has suggested that male dairy calves may receive a lower standard of care than their female counterparts due to their relatively low economic value (Renaud et al., 2017). A major priority for dairy farms in Great Britain $(\mathbf{G B})$ is to improve the growth and survival rate of youngstock 
and further increase the proportion of dairy bull calves entering the beef supply chain (CHAWG, 2017).

Previous studies have identified key farm management factors associated with calf morbidity including colostrum management practices, housing hygiene, and level of veterinary involvement (Windeyer et al., 2014; Johnson et al., 2017; Renaud et al., 2018), and several studies have estimated the effect of specific environmental conditions on mortality rates (Pannwitz, 2015; Hyde et al., 2020; Santman-Berends et al., 2021). Identifying key environmental and management factors associated with calf morbidity, mortality, and productivity is essential for veterinarians and farmers to implement effective management changes. Recent research has identified several key environmental and management factors associated with increased ADG on British dairy farms (Hyde et al., 2021), specifically environmental temperatures, housing hygiene, and milk/colostrum feeding practices. Management factors identified in previous studies to improve calf health and productivity outcomes have not been tested in a randomized controlled trial on dairy farms; this is essential to identify causal relationships and estimate the true effects of an intervention. It was hypothesized that a herd health plan involving these factors might be effective in improving calf health and production outcomes.

The objective of this study was to determine the effect of implementing an evidence-based calf health plan on both productivity and health outcomes for calves reared on dairy farms in GB.

\section{MATERIALS AND METHODS}

\section{Study Design and Farm Selection}

Sixty dairy farms in GB were recruited from a national supermarket supply group. Thirty-one of those farms were re-enrolled having previously been selected for a previous calf study after random selection and recruitment via telephone (Hyde et al., 2021). To recruit the remaining 29 farms that were required, 120 dairy farms were selected at random from the same national supermarket supply group. An informal letter was sent to the 114 farms with valid contact details and followed up with a telephone call through the farms in random order until the remaining 29 farms were recruited (92 farms contacted), resulting in a total of 60 farms recruited. Ethical approval was given by the University of Nottingham ethics committee (2119 170,911).

Farms were randomly allocated to 1 of 2 groups, either intervention (INT) or control (CON). Randomization was performed using the sample function in $\mathrm{R}$ ( $\mathrm{R}$ Core
Team, 2020) after grouping farms by geographical region [North $(\mathrm{n}=7)$, South $(\mathrm{n}=23)$, or Midlands $(\mathrm{n}=$ 30)] and recruitment group (farms re-enrolled from the previous trial and newly recruited farms), where INT farms would receive a calf health plan, and CON farms would receive the health plan after 6 mo. Blinding of the farmer and veterinarian providing the plan was not possible.

All farms were visited between December 4, 2019, and January 29, 2020, to conduct a calf management questionnaire (all questions are available at www.nottingham .ac.uk/herdhealthtoolkit, under "Calf health plan") and provide data collection training. During the initial visit, INT farms were provided with a calf health plan based on their responses to the management questionnaire, whereas CON farms received no calf health advice. Questionnaire responses were recorded separately for both male or beef calves (MB) and dairy heifer calves (DH) for all 20 questions.

\section{Calf Health Plan}

The calf health plan provided to INT farms was created using data from previously published research (Hyde et al., 2021), where key housing and management variables were identified as having the potential for major improvements on ADG on the majority of farms (Hyde et al., 2021). The calf health plan also contained interventions related to morbidity and mortality outcomes identified using the same data set and methodology (unpublished data). The final plan consisted of 20 possible interventions deemed to have the greatest potential to improve ADG, morbidity, and mortality rates. To determine which of the 20 interventions were appropriate for a given farm, the calf health plan was implemented using an online tool through the "Shiny" platform (Chang et al., 2021). The tool allowed the researcher and farmer to enter farmspecific management and housing information and be provided with a "traffic light" colored representation of current management practices as well as an automated written report, providing bespoke information and suggestions based on the data provided. An automated "Agreed recommendations" sheet was provided, with the top 10 interventions recommended by the health plan software. A full list of the possible interventions is provided in Figure 1, and all questions and interventions are available through the herd health toolkit (www.nottingham.ac.uk/herdhealthtoolkit, under "Calf health plan"). Farmers were encouraged to select and tick as many recommendations as they thought practical. Farmers were contacted at least monthly via phone 


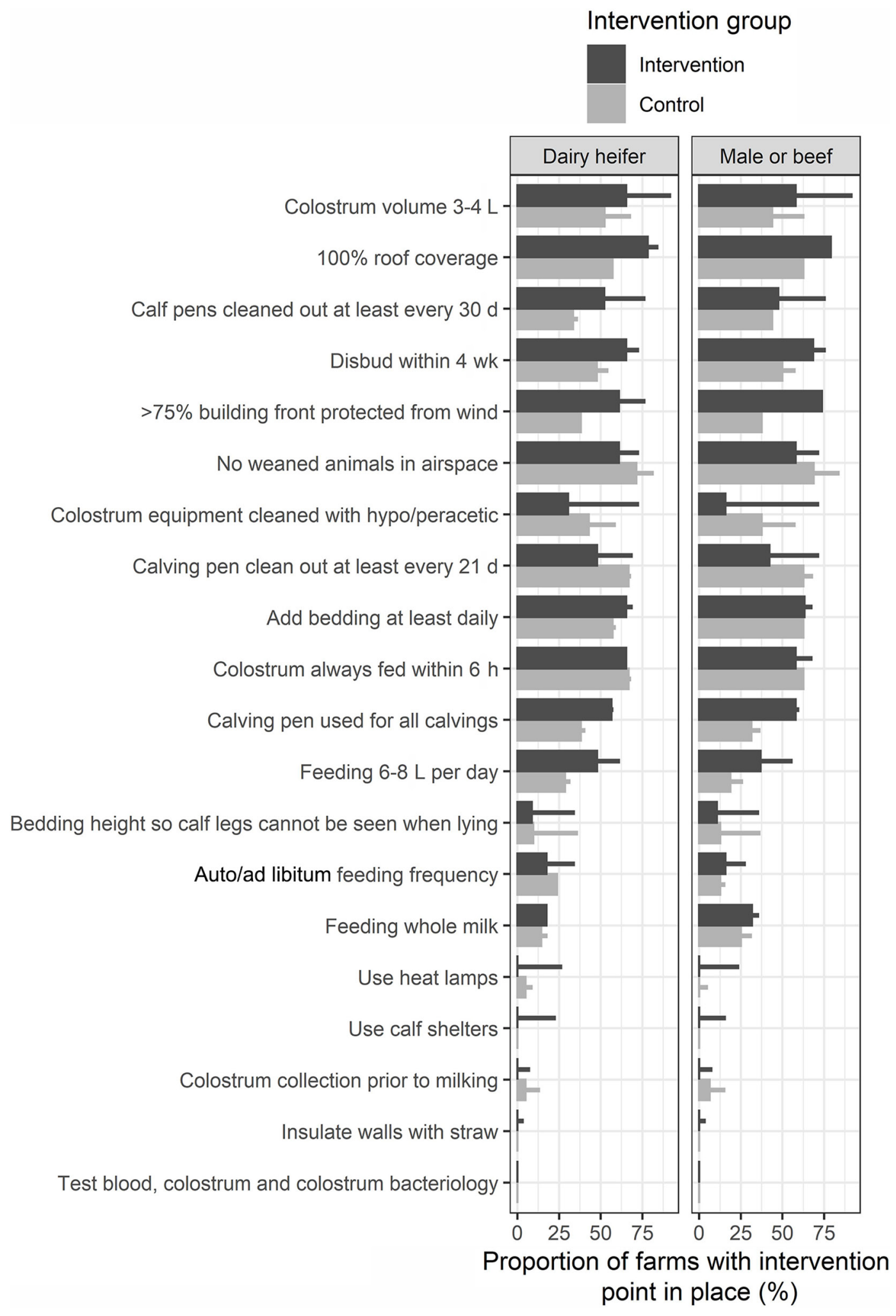

Figure 1. The proportion (\%) of calf health plan interventions in place on farms before (bar) and by the end (line) of the trial for dairy heifer (left) and male or beef calves (right), for intervention (dark) and control (light) farms, for all farms returning data from the 60 Great Britain dairy farms enrolled. For example, $65 \%$ of intervention farms were feeding the recommended 3 to $4 \mathrm{~L}$ of colostrum to dairy heifers at the start of the trial represented by the dark bar at the top of the dairy heifer panel, and by the end of the trial this had increased to $92 \%$ of intervention farms feeding the recommended 3 to $4 \mathrm{~L}$ of colostrum as shown by the dark line. 
call or SMS message throughout the trial period to encourage compliance with the implementation of the agreed interventions. An outline of the questionnaire themes is provided below.

Calving Pen. This section included the proportion of cows calving in a dedicated calving pen and the frequency of calving pen clean-out.

Colostrum. This section included questions relating to colostrum provision, including the length of time a calf might go without colostrum feeding, and how many liters would the calf receive in the first $6 \mathrm{~h}$ of life. This section also contained questions on the method and frequency of colostrum equipment cleaning.

Feeding. This area covered what the calves are fed (milk replacer or whole milk), and the volume and frequency of feed.

Housing. This section included the calf building design, including how much of it was covered by roof and sides, the frequency of clean-out, and both the frequency of application and nesting potential of bedding. This set of questions also covered whether any calf shelters or heat sources were present within the shed, whether animals shared airspace with any weaned animals, and the age of calf at disbudding.

All farms received training in the use of the weigh tapes provided for the trial (MSD) including a demonstration of their use during the farm visit and were instructed to record weights at birth and weaning for all calves born during the study period. To standardize the diagnosis of diarrhea and pneumonia, farmers received training in the use of a version of the Wisconsin calf health scoring system (McGuirk, 2008) that had previously been adapted for the United Kingdom (Johnson et al., 2017). Farmers were asked to record the date of any deaths, and the first case of diarrhea or pneumonia during the trial period so that an incidence risk might be calculated [i.e., each calf would be counted as either having "had" or "not had" diarrhea or pneumonia over the trial period (CDC, 2006)]. Farmers recorded data on a provided paper spreadsheet, and were asked to return data for analysis by the June 30, 2020, either electronically via digital photographs or by post using a prepaid envelope. Farms were removed from the trial if ADG could not be calculated due the absence of weighing dates at birth or weaning.

After the data collection phase of the trial was completed (June 30, 2020), farmers were contacted by telephone and the same management questionnaire was repeated to determine which housing and management practices had been in place during the trial. Where interventions had been implemented partway through the trial period, the management practice that had been in place for the majority of the study time was selected for analytic purposes.

\section{Statistical Analysis}

Descriptive and statistical analysis was conducted in $\mathrm{R}$ ( $\mathrm{R}$ Core Team, 2020). An a priori sample size calculation was performed, and a target of 60 farms was chosen to detect a change in mean farm ADG of at least $0.1 \mathrm{~kg} / \mathrm{d}$ based on a standard deviation of 0.13 and power of $80 \%$, with a significance level of 0.05 . Incidence risks for mortality and morbidity were calculated as the number of calves having a morbidity or mortality event within the first $90 \mathrm{~d}$ of life (numerator) out of the calves having a birthweight registered at least 90 $\mathrm{d}$ before the end of the trial (denominator). The ADG was estimated for calves where the difference in age between 2 weights was $>40 \mathrm{~d}$, to provide an estimation of ADG between birth and weaning. This resulted in 4 farm level outcomes for analysis, mean ADG between birth and weaning, and the percentage of calves experiencing diarrhea, pneumonia, or dying during the first $90 \mathrm{~d}$ of life. Incidence risks for morbidity, mortality, and mean ADG rates were calculated at farm level for separate management group groups: DH and MB. The number of health plan interventions being implemented both before the trial and during the trial period was calculated for both $\mathrm{DH}$ and $\mathrm{MB}$ groups.

A conventional, simple linear regression model (Kuhn and Johnson, 2013) was created from the data sample using the $l m$ function in $\mathrm{R}$ ( R Core Team, 2020) with mean ADG at farm level as model outcomes in separate models for dairy heifers and male or beef calves. Intervention group was provided as a fixed effect to evaluate the effect of the calf health plan. The number of interventions implemented were filtered to only include interventions that were in place on $\geq 20 \%$ of intervention or control farms and the number of interventions implemented over the trial period was tested as a fixed effect to evaluate the effect of the number of interventions implemented on calf health and performance. The linear regression models took the following form:

$$
Y_{i}=\mu+\beta_{1} X_{1 i}+\varepsilon
$$

where $Y_{i}$ was the mean ADG of the $i$ th farm, the fixed effect coefficient $\beta_{1}$ was either intervention group or number of interventions in the respective models for values $X_{1}$ of the $i$ th farm, $\mu$ represented the intercept, and $\varepsilon$ was the random error. The assumed distribution of $\varepsilon$ was normal, with mean zero and variance $\theta$. The coefficient of determination was calculated utilizing 5 -fold cross-validation (repeated 10 times) within the caret (Kuhn, 2018) package using held out (test) data. This was compared with the coefficient of determination calculated from internal model fit (i.e., without any cross-validation), to ensure the internal-calculated 
coefficient of determination was not dramatically increased compared with cross-validation calculated coefficient of determination (i.e., the model was not overfit). Residual distributions were checked visually to ensure model assumptions were met. To account for the proportional nature of morbidity and mortality outcomes at farm level, beta regression was used (Kieschnick and Mccullough, 2003) within the betareg package in R (Cribari-Neto and Zeileis, 2010). The proportion of calves born experiencing diarrhea, pneumonia, or death within the first $90 \mathrm{~d}$ of life was calculated at farm level $(0-1)$, and the following formula (Smithson and Verkuilen, 2006) was used to account for zeros or ones:

$$
y_{i}=\frac{y_{i}(n-1)+0.5}{n}
$$

where $y_{i}$ is either diarrhea, pneumonia, or mortality incidence risk at farm level as a proportion (0-1) of calves born having a case of disease or dying within the first $90 \mathrm{~d}$, for the $i$ th farm, and $n$ is the number of farms. The model structure of the ADG model was repeated for beta regression model outcomes, and coefficient of determination was determined using the pseudo Rsquared function. As beta regression coefficients are not as intuitive as coefficients from linear regression models, examples were provided by predicting disease rates from beta regression models for farms with the minimum and maximum number of interventions in place, as well as the mean number before the trial for all farms, and the mean number at the end of the trial for intervention farms.

\section{RESULTS}

Of the 60 farms enrolled, 14 failed to return any calf records. A total of 3,695 individual calf records were returned from 46 farms. After filtering to remove one farm with unusable records, there were 3,593 calf records from 45 farms (21 CON farms, 24 INT farms) ranging from 12 to 263 calves per farm. There were 1,760 calves with 2 weights recorded $>40 \mathrm{~d}$ apart $(955$ $\mathrm{DH}$ and $805 \mathrm{MB}$ calves) included for mean farm ADG calculations, and 1,871 calves born $>90 \mathrm{~d}$ before the end of the trial (856 DH and 1,015 MB calves) used as the denominator population for morbidity and mortality calculations. The breed type on all farms was predominantly Holstein Friesian, and calf management practices for control and intervention farms are presented in Figure 1.

The mean ADG for all calves was $0.78 \mathrm{~kg} / \mathrm{d}$, ranging from 0.33 to $1.13 \mathrm{~kg} / \mathrm{d}$, with mean incidence risks of $20.1 \%$ (0-96.6\%), $16.4 \%$ (0-95.2\%), and $4.3 \%$ (0-18.8\%) for diarrhea, pneumonia, and mortality, respectively. Median (interquartile range, IQR) ADG for all calves was $0.79 \mathrm{~kg} / \mathrm{d}$ (IQR $0.2 \mathrm{~kg} / \mathrm{d})$, with median incidence risks of $12.8 \%$ (IQR 22.3\%), 6.7\% (IQR 22.2\%), and $2.5 \%$ (IQR $7.0 \%$ ) for diarrhea, pneumonia, and mortality, respectively. As the questionnaire was conducted with the farmer in person using the herd health toolkit app, farmers answered all required questions. The INT farms had a higher number of interventions in place by the end of the trial (Table 1). The INT farms had a mean of 7.4 interventions in place at the start of the trial, and 9.9 interventions at the end of the trial. The CON farms had a mean of 6.6 interventions in place at the start of the trial, and 7.6 at the end of the trial, despite being given no advice to put any interventions into place. The percentage of $\mathrm{CON}$ and INT farms carrying out recommended interventions at the start and end of the trial are shown in Figure 1. Three interventions were identified as being in place on $<20 \%$ of intervention farms (colostrum collection time being before, during, or after the milking of the rest of the herd; insulating concrete walls with straw; and routine testing of colostrum or blood to ensure passive transfer) and were removed for the analysis of the association between the number of interventions in place and calf health and production outcomes.

Mean farm ADG was numerically higher in the intervention group for both MB calves and DH calves (Table 1). Model results (Table 2) indicated that the intervention group was associated with a significant increase in mean ADG for male and beef calves of $0.12 \mathrm{~kg} / \mathrm{d}(95 \%$ CI: $0.02-0.22, P=0.03)$. No significant associations were observed between intervention group for mortality or morbidity outcomes (Table 2).

The number of interventions in place on a farm, irrespective of intervention group, was significantly associated with several health and production outcomes (Table 2, Figure 2), regardless of which specific intervention was in place. An increased number of interventions in place was associated with an increase in mean ADG for DH calves of $0.01 \mathrm{~kg} / \mathrm{d}(95 \%$ CI: $0-0.03, P=$ $0.04)$ and MB calves of $0.02 \mathrm{~kg} / \mathrm{d}$ (95\% CI: $0.00-0.04, P$ $=0.10)$ per intervention implemented. The farms with the highest number of interventions in place (15) might expect a mean farm ADG of rate of 0.88 and $0.81 \mathrm{~kg} / \mathrm{d}$ for $\mathrm{DH}$ and $\mathrm{MB}$ calves compared with 0.73 and 0.65 $\mathrm{kg} / \mathrm{d}$ on farms with the lowest number of interventions in place (4) for DH and MB calves, respectively. Coefficients for morbidity and mortality models are presented in Table 2; however, because coefficients for beta regression models are not intuitively interpretable, examples of changes in morbidity and mortality rates associated with the number of interventions in place are presented here. An increased number of interventions in place was 
Hyde et al.: IMPROVING GROWTH RATES IN PREWEANING CALVES
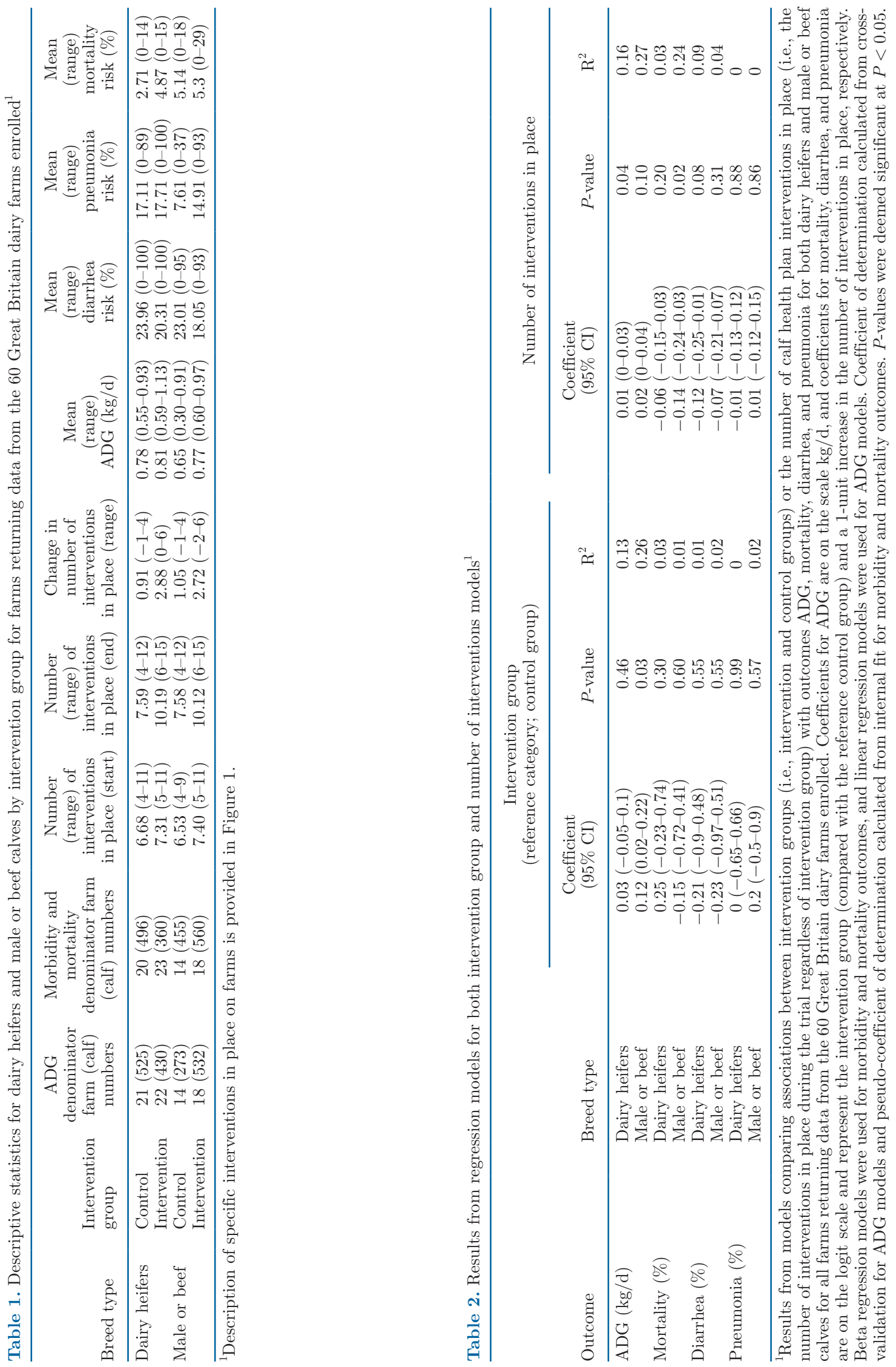
associated with a significant decrease in mortality rates for MB calves $(P=0.02)$. For example, the predicted mortality rate on a farm with 7 (mean number of interventions in place for all farms at the start of the trial) interventions in place would be expected to decrease from $7.6 \%$ mortality to $5.2 \%$ mortality if they increased the number of interventions in place to 10 (mean number of interventions in place for intervention farms at the end of the trial) based on model predictions. The farms with the highest number of interventions in place (15) might expect a mortality rate of rate of $2.8 \%$ compared with $10.9 \%$ for farms with the lowest number of interventions in place (4). There was a tendency $(P=$ 0.08 ) for an association between an increased number of interventions in place and a decrease in diarrhea rates for $\mathrm{DH}$ calves, and a farm increasing from 7 to 10 interventions might expect a reduction in diarrhea incidence risk from $33.1 \%$ to $25.2 \%$. The farms with the highest number of interventions in place (15) might expect a diarrhea rate of $15.1 \%$ compared with $42.1 \%$ for farms with the lowest number of interventions in place (4). No significant associations were found between the number of interventions in place and pneumonia risk. Statistical analysis was repeated including the single removed farm to check that no significant changes in results occurred; this was found to have no effect.

\section{DISCUSSION}

This study explored the effect of implementing an evidence-based calf health plan on health and productivity outcomes on dairy farms in GB. The results from this study suggest that the implementation of a calf health plan has the potential to improve ADG for preweaning calves, particularly beef cross and dairy bull calves, with each additional intervention in place being associated with improvements in mean ADG, diarrhea, and mortality rates. With relatively high rates of morbidity and mortality (Table 1), and a national focus on improving youngstock health and productivity (CHAWG, 2017), the calf health plan tested in this study represents a potentially useful tool to aid veterinarians and farmers in the implementation of effective management interventions likely to improve the health, welfare, and productivity of preweaning calves on GB dairy farms.

Interventions utilized in this calf health plan were largely based on findings from a recent study identifying factors associated with mean farm ADG (Hyde et al., 2021) and were predominantly based around increased feeding levels, limiting the effect of cold stress and improving hygiene. Increased levels of milk feeding and, in particular, the feeding of whole milk, has been previously identified in several studies as being associated with improved health and production outcomes in preweaning calves (Medrano-Galarza et al., 2018; Shivley et al., 2018; Dubrovsky et al., 2019a,b). Despite the added cost of feeding increased levels of milk, it is likely that feeding increased levels of milk would be cost-beneficial in the majority of cases (Dubrovsky et al., 2020), and the feeding of pasteurized whole milk may be an economically viable strategy for dairy farms (Godden et al., 2005). Calves housed in environmental temperatures outside of their thermoneutral zone are likely to experience heat or cold stress, which could result in direct economic losses through increased calf morbidity and mortality as well as reduced weight gain and performance (Roland et al., 2016) and so this should, therefore, be minimized to maximize calf performance and welfare (Silanikove, 2000). Neonatal calves are prone to heat loss under cold conditions due to their low surface area to mass ratio (Berman, 2003), and are unable to rely on heat production from ruminal fermentation (Collier et al., 1982). In many countries, including Britain, the temperature in calf housing is often below the thermoneutral zone of neonatal calves for a large proportion of the year, with recorded temperatures within calf housing being similar to the recorded ambient temperature (Hyde et al., 2021). Despite the apparent need for increased environmental temperatures within calf housing, care must be taken when altering buildings for improved heat retention, as housing systems that succeed in providing thermal comfort may be predisposed to other problems such as poor air quality (Roland et al., 2016), and previous studies have suggested that it is preferable to manage cold stress with the provision of sufficient bedding for nesting rather than the enclosure of pens with solid sides (Lago et al., 2006). The use of external heat sources to increase environmental temperatures has been previously explored, and previous research has suggested that calves show preference for areas under the heat lamp (Borderas et al., 2009) suggesting there is a positive welfare component to the provision of additional heat. These previous studies provide support for the interventions used in this calf health plan relating to the provision of external heat sources and increased bedding provision to allow sufficient nesting. Interventions to improve the housing environment may be beneficial in decreasing the deleterious effects of cold stress on calves in the first few weeks of life. Several housing factors such as the frequent provision of fresh bedding, the use of a maternity pen for calving only (Medrano-Galarza et al., 2018), the avoidance of shared airspace with weaned animals, and housing under a roof (Maier et al., 2019) have all been previously found to have a positive effect on calf health outcomes. The provision of clean bedding has also been found to be 


\section{Intervention group}

- Intervention

- Control
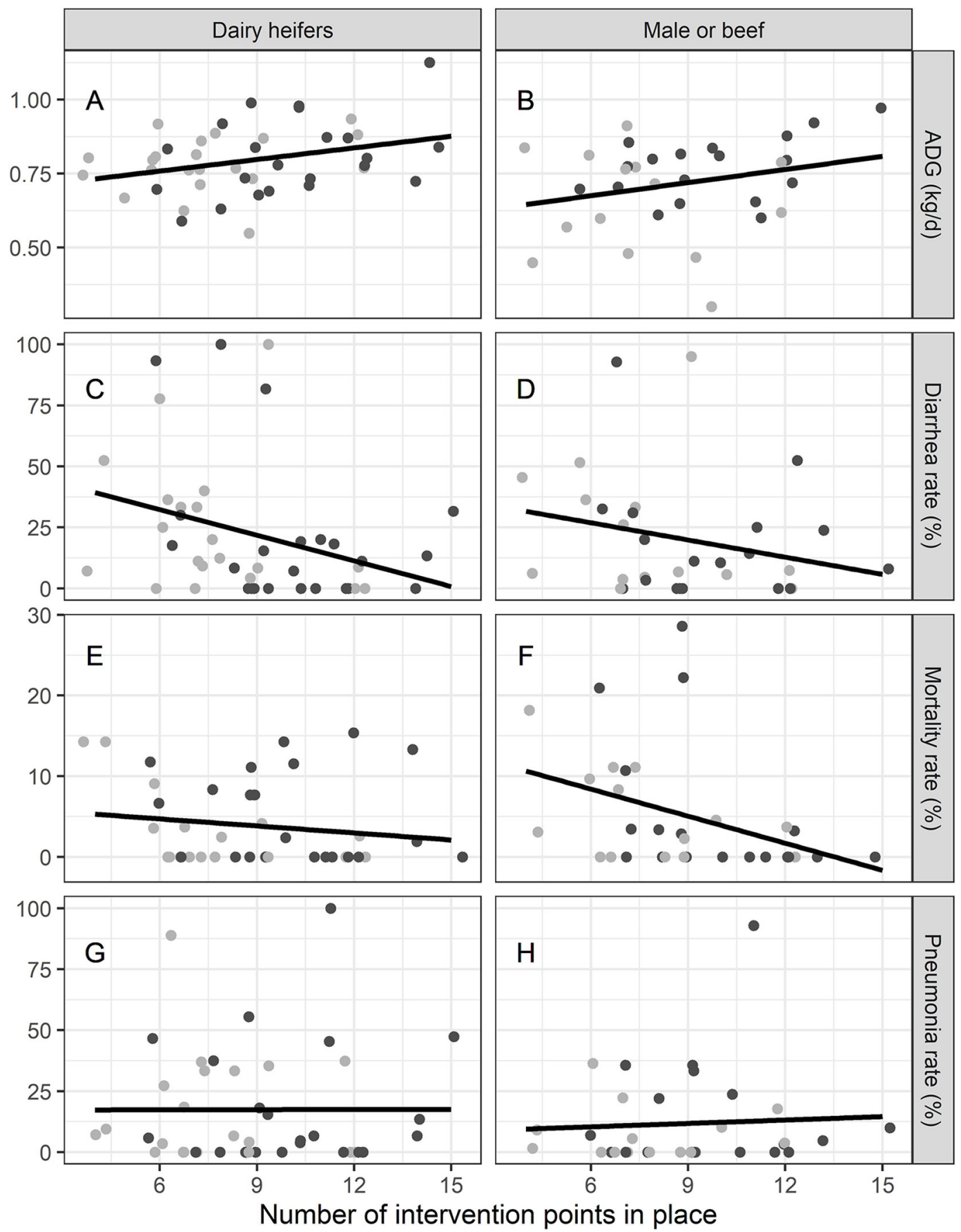

Figure 2. Associations between the number of calf health plan interventions in place and ADG, diarrhea, mortality, and pneumonia rates (panels top to bottom, A and B represent ADG, C and D represent diarrhea rate, $\mathrm{E}$ and $\mathrm{F}$ represent mortality rate, and $\mathrm{G}$ and $\mathrm{H}$ represent pneumonia rate) for beef or bull calves (right panels B, D, F, and H) and dairy heifer calves (left panels, A, C, E, and G) on intervention (dark points) and control (light points) farms. Each point represents the growth, morbidity, or mortality levels for a given farm colored by their intervention group (intervention or control) with a regression line, for all farms returning data from the 60 Great Britain dairy farms enrolled. 
associated with increased ADG in preweaning calves (Quigley et al., 2017).

Although we did not identify clear improvements in disease outcomes in farms that implemented the calf health plan, the relatively low number of additional interventions implemented by farms in the intervention group suggests that farmer engagement may play an important role in the potential efficacy of a health plan. This research demonstrated that increasing the number of interventions on a farm is associated with improvements in mean farm ADG, diarrhea, and mortality rates for preweaning calves, but that farmers may be hesitant to implement more than 2 to 3 interventions over a short time period, limiting the short-term efficacy of the plan. It is likely that small incremental improvements in housing and management over a longer period of time will be beneficial in improving calf health and performance.

Both intervention and control farms reported an increased number of interventions in place at the end of the trial (Table 1), suggesting that simply by benchmarking farms, improvements in management practices are likely even where no specific advice has been given. In particular, increased levels of bedding and colostrum to calves were relatively commonly improvements made on control farms over the trial period (Figure 1), even though no specific advice was provided to do so. This is supported by a previous study that reported an improvement in ADG following the benchmarking of farms, suggesting that the monitoring and benchmarking of calf outcomes might be an effective starting point to improve calf management protocols in practice, irrespective of any additional advice given (Atkinson et al., 2017).

While the efficacy of interventions is clearly important, the practicality of potential interventions and, therefore, farmer willingness to implement a specific intervention is also of importance in the design of a calf health plan. Removal of interventions not commonly implemented has resulted in a more parsimonious plan, which should allow farmers to focus on the smallest number of interventions with the largest potential for positive effect on health and productivity outcomes. The approach taken in this study was based on a risk management tool, consisting of a web-app-based interface with 20 simple questions and resulting in a clear list of management factors to focus on. The automated nature of the report means that it is very time efficient to implement and does not require any additional reports to be written as might be typical after a health plan meeting.

Whereas improvements in mean ADG, diarrhea, and mortality rates have been shown to be associated with an increased number of interventions implemented, no significant associations were observed with pneumonia rates. Despite training in the use of a standardized calf health scoring system, there was likely to be substantial variations in farmer detection rates for pneumonia, and the sensitivity of respiratory disease detection based on clinical signs was found to be only $27 \%$ in a recent metaanalysis (Timsit et al., 2016). Even with a standardized scoring system, the pneumonia rates reported during both the current study and the previous study are likely to be influenced by farmer detection capability. The detection of small differences in both disease rates and mean ADG is also likely to be limited by sample size constraints. High standard deviations in morbidity and mortality rates meant that only relatively large differences could be detected between groups, and a lack of significant associations between intervention group and morbidity or mortality outcomes may again represent insufficient power rather than a true lack of association. With a standard deviation of mean farm ADG of 0.15 and $0.11 \mathrm{~kg} / \mathrm{d}$ and farm numbers of 32 and 43 , a difference in mean farm ADG of 0.11 and $0.07 \mathrm{~kg} / \mathrm{d}$ would be detectable for $\mathrm{MB}$ and $\mathrm{DH}$ calves respectively, with a power of $80 \%$ and significance level at 0.05 . Therefore, although mean ADG improvements for $\mathrm{DH}$ calves on intervention farms did not reach significance by conventional thresholds, this is potentially due to a lack of power and an increased sample size may be required to detect this smaller improvement in mean ADG. It may also have been challenging to detect differences in growth rates for $\mathrm{DH}$ calves, which grew at a relatively high rate in the control group $(0.78 \mathrm{~kg} / \mathrm{d})$. It would be challenging to dramatically increase growth rates far in excess of this relatively high starting figure using the current plan. The MB calves, however, had a far lower mean farm ADG in the control group $(0.65 \mathrm{~kg} / \mathrm{d})$ and, therefore, had far greater potential for improvement in the intervention group. Farm factors not included in the plan are also likely to be influential in ADG rates, in particular the age of weaning due to the nonlinear nature of preweaning growth rates (Bazeley et al., 2016). A potential limitation of the modeling approach is that an intervention was considered implemented if it was in place for the majority of the recording period.

Although farmers were selected at random for the opportunity to participate in the research project, the voluntary nature of trial enrolment may have resulted in the selection of relatively proactive farmers and, therefore, a degree of bias. Although there are some limitations in farm recruitment because the inclusion within the supermarket group was initially based on convenient milk supply routes, any selection bias is likely to be limited and the sample is likely to be relatively representative of GB dairy farms. Some farms were recruited after previous enrolment, again potentially 
selecting for farmers that were more engaged in the previous study. Farmer recorded mortality $(4.28 \%)$ was, however, similar to national mortality levels reported previously (3.87\%; Hyde et al., 2020) suggesting that this sample is representative of GB and that farmer recording accuracy was likely to be relatively high. Caution should be taken, however, when extrapolating the results from this trial to other countries, which may have different health plan requirements than calves on GB dairy farms.

The coefficient of determination figures provided (Table 2) suggest that whereas a reasonable proportion of the variation in health and production outcomes might be accounted for by either the intervention group or the number of interventions in place, there are likely to be other important farm and animal level factors that also bear consideration. Although this plan was designed to give relatively rapid improvements to growth rates, it is likely that improvements in mean farm ADG are highly multifactorial, and the plan should be used as a guide and starting point rather than a holistic health plan.

\section{CONCLUSIONS}

This research has demonstrated that implementation of a calf health plan is likely to improve mean farm ADG for preweaning calves on GB dairy farms, particularly MB calves, with each additional intervention undertaken being associated with improvements in mean farm ADG, diarrhea, and mortality rates. The improvements in management practices made on control farms despite no advice being given suggests that simply monitoring and benchmarking calf health performance might be a useful starting point to improve calf health and performance, with the calf health plan forming a template for further improvements to the housing and management of preweaning calves. The calf health plan tested in this study represents a potentially useful tool to aid veterinarians and farmers in the implementation of effective management interventions likely to improve the health, welfare, and productivity of preweaning calves on GB dairy farms. The health plan and reporting framework are freely available open access at www.nottingham.ac .uk/herdhealthtoolkit.

\section{ACKNOWLEDGMENTS}

The authors have not stated any conflicts of interest. This research was carried out as part of a wider calf health research project funded by the Agricultural and Horticulture Development Board (AHDB; Warwickshire, UK), the AgriFood Charities Partnership (Bedford, UK), and the University of Nottingham School of Veterinary Medicine and Science (Leicester- shire, UK). Thanks to MSD (Milton Keynes, UK) for providing weigh tapes for use in the trial, and to all farmers involved in the trial for their contributions and commitment.

\section{REFERENCES}

Atkinson, D. J., M. von Keyserlingk, and D. Weary. 2017. Benchmarking passive transfer of immunity and growth in dairy calves. J. Dairy Sci. 100:3773-3782. https://doi.org/10.3168/jds.2016-11800.

Atkinson, O. 2015. To survey current practices and performance and to determine the success factors for rearing replacement dairy heifers in Wales. Welsh Dairy Youngstock Project, full report. Dairy Veterinary Consultancy Ltd. Accessed Oct. 27, 2021. https: // dairyveterinaryconsultancy.co.uk/download/the-welsh-dairy -youngstock-project-full-report/.

Bazeley, K. J., D. C. Barrett, P. D. Williams, and K. K. Reyher. 2016. Measuring the growth rate of UK dairy heifers to improve future productivity. Vet. J. 212:9-14. https://doi.org/10.1016/j.tvjl.2015 .10 .043 .

Berman, A. 2003. Effects of body surface area estimates on predicted energy requirements and heat stress. J. Dairy Sci. 86:3605-3610. https://doi.org/10.3168/jds.S0022-0302(03)73966-6.

Borderas, F. T., A. M. B. de Passillé, and J. Rushen. 2009. Temperature preferences and feed level of the newborn dairy calf. Appl. Anim. Behav. Sci. 120:56-61. https://doi.org/10.1016/j.applanim .2009.04.010.

Boulton, A. C., J. Rushton, and D. C. Wathes. 2017. An empirical analysis of the cost of rearing dairy heifers from birth to first calving and the time taken to repay these costs. Animal 11:1372-1380. https://doi.org/10.1017/S1751731117000064.

Brickell, J., M. M. McGowan, D. U. Pfeiffer, and D. C. Wathes. 2009. Mortality in Holstein-Friesian calves and replacement heifers, in relation to body weight and IGF-I concentration, on 19 farms in England. Animal 3:1175-1182. https://doi.org/10.1017/ S175173110900456X.

CDC (Centers for Disease Control and Prevention). 2006. Principles of Epidemiology in Public Health Practice, Third Edition: An Introduction. Accessed Jul. 27, 2021. https://www.cdc.gov/csels/ dsepd/ss1978/index.html.

Chang, W., C. Joe, J. Allaire, C. Sievert, B. Schloerke, Y. Xie, J. Allen, J. McPherson, A. Dipert, and B. Borges. 2021. shiny: Web Application Framework for R. R Packag. Version 1.6.0. https:// cran.r-project.org/web/packages/shiny/index.html.

CHAWG. 2017. Dairy Cow Welfare Strategy. Accessed Nov. 17 2020. https://ahdb.org.uk/knowledge-library/dairy-cow-welfare -strategy.

Collier, R. J., D. K. Beede, W. W. Thatcher, L. A. Israel, and C. J. Wilcox. 1982. Influences of environment and its modification on dairy animal health and production. J. Dairy Sci. 65:2213-2227. https://doi.org/10.3168/jds.S0022-0302(82)82484-3.

Cribari-Neto, F., and A. Zeileis. 2010. Beta regression in R. J. Stat. Softw. 34:1-24. https://doi.org/10.18637/jss.v034.i02.

Dubrovsky, S. A., A. L. Van Eenennaam, S. S. Aly, B. M. Karle, P. V. Rossitto, M. W. Overton, T. W. Lehenbauer, and J. G. Fadel. 2020. Preweaning cost of bovine respiratory disease (BRD) and cost-benefit of implementation of preventative measures in calves on California dairies: The BRD 10K study. J. Dairy Sci. 103:15831597. https://doi.org/10.3168/jds.2018-15501.

Dubrovsky, S. A., A. L. Van Eenennaam, B. M. Karle, P. V. Rossitto, T. W. Lehenbauer, and S. S. Aly. 2019a. Epidemiology of bovine respiratory disease (BRD) in preweaned calves on California dairies: The BRD 10K study. J. Dairy Sci. 102:7306-7319. https://doi .org/10.3168/jds.2018-14774.

Dubrovsky, S. A., A. L. Van Eenennaam, B. M. Karle, P. V. Rossitto, T. W. Lehenbauer, and S. S. Aly. 2019b. Bovine respiratory disease (BRD) cause-specific and overall mortality in preweaned calves on California dairies: The BRD 10K study. J. Dairy Sci. 102:7320-7328. https://doi.org/10.3168/jds.2018-15463. 
Godden, S. M., J. P. Fetrow, J. M. Feirtag, L. R. Green, and S. J. Wells. 2005. Economic analysis of feeding pasteurized nonsaleable milk versus conventional milk replacer to dairy calves. J. Am. Vet. Med. Assoc. 226:1547-1554. https://doi.org/10.2460/javma.2005 .226 .1547 .

Hultgren, J., and C. Svensson. 2009. Heifer rearing conditions affect length of productive life in Swedish dairy cows. Prev. Vet. Med. 89:255-264. https://doi.org/10.1016/j.prevetmed.2009.02.012.

Hyde, R. M., M. Green, C. Hudson, and P. Down. 2021. Factors associated with daily weight gain in preweaned calves on dairy farms. Prev. Vet. Med. 190:105320. https://doi.org/10.1016/j.prevetmed .2021.105320.

Hyde, R. M., M. Green, V. Sherwin, C. Hudson, J. Gibbons, T. Forshaw, M. Vickers, and P. Down. 2020. Quantitative analysis of calf mortality in Great Britain. J. Dairy Sci. 103:2615-2623. https:// doi.org/10.3168/jds.2019-17383.

Johnson, K. F., N. Chancellor, C. C. Burn, and D. C. Wathes. 2017. Prospective cohort study to assess rates of contagious disease in pre-weaned UK dairy heifers: Management practices, passive transfer of immunity and associated calf health. Vet. Rec. Open 4:e000226. https://doi.org/10.1136/vetreco-2017-000226.

Kieschnick, R., and B. D. Mccullough. 2003. Regression analysis of variates observed on $(0,1)$ Percentages, proportions and fractions. Stat. Model. 3:193-213. https://doi.org/10.1191/ 1471082X03st053oa.

Kuhn, M., and K. Johnson. 2013. Applied Predictive Modeling. Springer.

Kuhn, M. 2018. caret: Classification and Regression Training. R package.

Lago, A., S. M. M. McGuirk, T. B. B. Bennett, N. B. B. Cook, and K. V. V. Nordlund. 2006. Calf respiratory disease and pen microenvironments in naturally ventilated calf barns in winter. J. Dairy Sci. 89:4014-4025. https://doi.org/10.3168/jds.S0022-0302(06)72445 -6 .

Maier, G. U., W. J. Love, B. M. Karle, S. A. Dubrovsky, D. R. Williams, J. D. Champagne, R. J. Anderson, J. D. Rowe, T. W. Lehenbauer, A. L. Van Eenennaam, and S. S. Aly. 2019. Management factors associated with bovine respiratory disease in preweaned calves on California dairies: The BRD 100 study. J. Dairy Sci. 102:7288-7305. https://doi.org/10.3168/jds.2018-14773.

McGuirk, S. M. 2008. Disease management of dairy calves and heifers. Vet. Clin. North Am. Food Anim. Pract. 24:139-153. https://doi .org/10.1016/j.cvfa.2007.10.003.

Medrano-Galarza, C., S. J. LeBlanc, A. Jones-Bitton, T. J. DeVries, J. Rushen, A. Marie de Passillé, M. I. Endres, and D. B. Haley. 2018. Associations between management practices and within-pen prevalence of calf diarrhea and respiratory disease on dairy farms using automated milk feeders. J. Dairy Sci. 101:2293-2308. https: //doi.org/10.3168/jds.2017-13733.

Mõtus, K., K. Reimus, T. Orro, A. Viltrop, and U. Emanuelson. 2017. On-farm mortality, causes and risk factors in Estonian beef cowcalf herds. Prev. Vet. Med. 139:10-19. https://doi.org/10.1016/j .prevetmed.2016.10.014.

Pannwitz, G. 2015. Standardized analysis of German cattle mortality using national register data. Prev. Vet. Med. 118:260-270. https:/ /doi.org/10.1016/j.prevetmed.2014.11.020.
Quigley, J. D., T. M. Hill, L. L. Deikun, and R. L. Schlotterbeck. 2017. Effects of amount of colostrum replacer, amount of milk replacer, and housing cleanliness on health, growth, and intake of Holstein calves to 8 weeks of age. J. Dairy Sci. 100:9177-9185. https://doi .org/10.3168/jds.2017-12784.

R Core Team. 2020. R: A Language and Environment for Statistical Computing. R Foundation for Statistical Computing.

Renaud, D. L., T. Duffield, S. LeBlanc, D. Haley, and D. Kelton. 2017. Management practices for male calves on Canadian dairy farms. J. Dairy Sci. 100:6862-6871. https://doi.org/10.3168/jds.2017-12750.

Renaud, D. L., D. F. Kelton, S. J. LeBlanc, D. B. Haley, and T. F. Duffield. 2018. Calf management risk factors on dairy farms associated with male calf mortality on veal farms. J. Dairy Sci. 101:1785-1794. https://doi.org/10.3168/jds.2017-13578.

Roland, L., M. Drillich, D. Klein-Jöbstl, and M. Iwersen. 2016. Invited review: Influence of climatic conditions on the development, performance, and health of calves. J. Dairy Sci. 99:2438-2452. https: //doi.org/10.3168/jds.2015-9901.

Santman-Berends, I. M. G. A. M. G. A., G. H. H. Nijhoving, L. van Wuijckhuise, J. Muskens, I. Bos, and G. van Schaik. 2021. Evaluation of the association between the introduction of data-driven tools to support calf rearing and reduced calf mortality in dairy herds in the Netherlands. Prev. Vet. Med. 191:105344. https://doi .org/10.1016/j.prevetmed.2021.105344.

Shivley, C. B., J. E. Lombard, N. J. Urie, C. A. Kopral, M. Santin T. J. Earleywine, J. D. Olson, and F. B. Garry. 2018. Preweaned heifer management on US dairy operations: Part VI. Factors associated with average daily gain in preweaned dairy heifer calves. J. Dairy Sci. 101:9245-9258. https://doi.org/10.3168/jds.2017-14022.

Silanikove, N. 2000. Effects of heat stress on the welfare of extensively managed domestic ruminants. Livest. Prod. Sci. 67:1-18. https:// doi.org/10.1016/S0301-6226(00)00162-7.

Smithson, M., and J. Verkuilen. 2006. A better lemon squeezer? Maximum-likelihood regression with beta-distributed dependent variables. Psychol. Methods 11:54-71. https://doi.org/10.1037/1082 -989X.11.1.54.

Timsit, E., N. Dendukuri, I. Schiller, and S. Buczinski. 2016. Diagnostic accuracy of clinical illness for bovine respiratory disease (BRD) diagnosis in beef cattle placed in feedlots: A systematic literature review and hierarchical Bayesian latent-class meta-analysis. Prev. Vet. Med. 135:67-73. https://doi.org/10.1016/j.prevetmed.2016.11 .006 .

Windeyer, M. C., K. E. Leslie, S. M. Godden, D. C. Hodgins, K. D. Lissemore, and S. J. LeBlanc. 2014. Factors associated with morbidity, mortality, and growth of dairy heifer calves up to 3 months of age. Prev. Vet. Med. 113:231-240. https://doi.org/10.1016/j .prevetmed.2013.10.019.

\section{ORCIDS}

Robert M. Hyde @ https://orcid.org/0000-0002-8705-9405 Martin J. Green (ㄴ https://orcid.org/0000-0002-6408-6443 Chris Hudson ๑ https://orcid.org/0000-0003-4777-062X Peter M. Down ๑ https://orcid.org/0000-0003-1896-7255 